Paper

\title{
Effect of Sintering Temperature on Density, Hardness and Strength of MIM Co30Cr6Mo Biomedical Alloy
}

\author{
Azizah WAHI ${ }^{1}$, Norhamidi MUHAMAD ${ }^{1}$, Abu Bakar SULONG ${ }^{1}$ and Rozie Nani AHMAD ${ }^{2}$
}

${ }^{1}$ Faculty of Engineering \& Built Environment, Universiti Kebangsaan Malaysia, 43600 Bangi, Selangor, Malaysia. ${ }^{2}$ School of Manufacturing Engineering, Universiti Malaysia Perlis, Campus Tetap Pauh Putra, Jalan Arau-Changlun, 02600 Arau, Perlis, Malaysia.

Received November 30, 2015; Revised March 10, 2016; Accepted March 16, 2016

\begin{abstract}
This paper reports on the effect of sintering temperature on the density, hardness and strength of Co30Cr6Mo fabricated by Metal Injection Molding (MIM). Palm stearin and polyethylene have been used as the binder system. The feedstock was injected by injection molding machine to produced micro dumbbell shape part. The specimens were solvent debound in n-hepthane for 15 minutes and thermally debound in argon atmosphere for an hour. The sintering was carried out in vacuum furnace at temperature $1250{ }^{\circ} \mathrm{C}, 1300{ }^{\circ} \mathrm{C}$ and $1350{ }^{\circ} \mathrm{C}$ for an hour. The density, hardness and tensile strength were then measured. The specimens that have been sintered at $1350{ }^{\circ} \mathrm{C}$ showed highest density and tensile strength compared with samples sintered at $1250{ }^{\circ} \mathrm{C}$ and $1300{ }^{\circ} \mathrm{C}$. The samples which has been sintered at $1350^{\circ} \mathrm{C}$ has highest relative density $(93 \%)$, compared with the same sample sintered at $1250{ }^{\circ} \mathrm{C}(87 \%)$ and $1300{ }^{\circ} \mathrm{C}(76 \%)$. As the temperature increased, the tensile strength increased gradually $400 \mathrm{MPa}$ to $700 \mathrm{MPa}$ and the micro hardness also increased from $200 \mathrm{Hv}$ to $540 \mathrm{Hv}$. The morphology of sintered specimen showed that the morphological bonding between powder particles becomes denser at highest sintering temperature of $1350^{\circ} \mathrm{C}$.
\end{abstract}

KEY WORDS

CoCrMo alloys, sintering, mechanical properties, injection molding

\section{Introduction}

Co30Cr6Mo alloy possesses excellent mechanical properties, non-magnetic behavior, excellent wear resistance, and good biocompatibility. Therefore, this alloy is commonly employed for biomedical industries, such as prosthetic replacement of knee joint, elbows, fingers, bone plates, screws, rods and dental implants ${ }^{1)}$. Co30Cr6Mo is commonly produced by casting. However small complex parts is hardly produced by casting method. Therefore, many researchers choose alternative methods such as powder metallurgy for CoCrMo metal fabrication ${ }^{2}$. Powder metallurgy process can produced sufficient green density, low porosity, considerable hardness of $\mathrm{Co} 30 \mathrm{Cr} 6 \mathrm{Mo}^{3}$. Combination of powder metallurgy and injection molding is another suggestion of alternative method to produced Co30Cr6Mo part.

The metal injection molding (MIM) process is a high potential economic process for mass production of complex microparts which can overcome the limitations of casting products ${ }^{4}$. MIM process involves mixing, injection molding, debinding and sintering. In the mixing step, the powder is mixed with binders to form feedstock. The feedstock is then injected to cavity. In the

\footnotetext{
* Corresponding author, E-mail: azizahwahi@siswa.ukm.edu.my
}

debinding step, the binders are removed. Finally, the parts are sintered. Sintering is a key step in injection molding process that affects the mechanical properties of the sintered part. Various parameters such as temperature and sintering atmosphere have been optimized in order to achieve high density part. This paper will focused on the effect of sintering temperature to mechanical properties of sintered Co30Cr6Mo produced by MIM.

\section{Materials and Methods}

The raw material used was water-atomized Co30Cr6Mo powder with approximately 20 microns of average particle. The 67 vol.\% powder loading Co30Cr6Mo with 40 vol.\% palm stearin and 60 vol.\% LDPE feedstock were prepared. The injection parameters were temperature $180^{\circ} \mathrm{C}$, injection pressure 10 bars, mold temperature $100{ }^{\circ} \mathrm{C}$, packing time $7 \mathrm{~s}$, and the injection time $5 \mathrm{~s}$. The polymer binder was removed through solvent debinding, followed by thermal debinding. Solvent debinding was carried out to remove palm stearin. In solvent debinding, the green part was immersed in low molecular n-heptanes at $60{ }^{\circ} \mathrm{C}$, which was slightly higher than the melting point of palm stearin in a furnace dryer WTB binder (model 950204). The parts were thermally debound for approximately $1 \mathrm{~h}$ at $450{ }^{\circ} \mathrm{C}$ with $2{ }^{\circ} \mathrm{C} / \mathrm{min}$ heating 

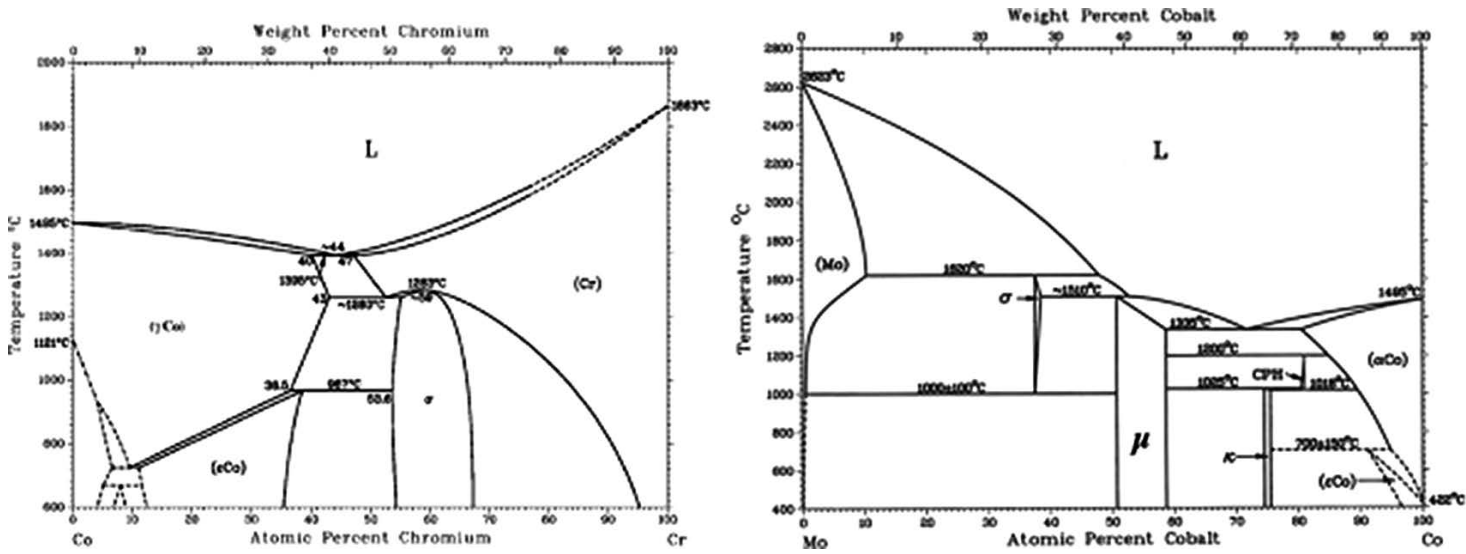

Fig. 1 Phase diaghram of (a) Co-Cr and (b) Co-Mo.

rate in argon atmosphere. Based on the manufacturer information, the melting point of $\mathrm{Co} 30 \mathrm{Cr} 6 \mathrm{Mo}$ powder is $1390^{\circ} \mathrm{C}$. While based on the $\mathrm{Co}-\mathrm{Cr}$ phase diagram in Fig. 1, the eutectic temperature is $1395^{\circ} \mathrm{C}$. The melting point of cobalt and molybdenum was $2623{ }^{\circ} \mathrm{C}$ and $1495{ }^{\circ} \mathrm{C}$ respectively; however, the eutectic mixture was created at $1335^{\circ} \mathrm{C}$ for $40 \mathrm{wt} \%$ Mo, which may be the cause of low the melting point of the examined alloy). In this study, sintering was held in a vacuum furnace at three sintering conditions at 1250,1300 and $1350{ }^{\circ} \mathrm{C}$ for 2 hours, with heating rate $2{ }^{\circ} \mathrm{C} / \mathrm{min}$ Other researchers reported that low heating rate was chosen to avoid rapid pressure gradient that may result in cracks or defects ${ }^{5,6)}$. The effect of sintering temperature was documented below.

\section{Results and Discussions}

During sintering, the void spaces between the powder particles were removed, causing densification and shrinkage of the component. A perfect sintered part at $1350{ }^{\circ} \mathrm{C}$ was observed without any cracks or defects, as shown in Fig. 2.

Sintering is the most influential step in dimensional variation, in which shrinkage could range from $14 \%$ to $24 \%{ }^{7}$. The calculated longitudinal dimension shrinkage ranged from $10 \%$ to $14 \%$ in this study. Low shrinkage is due high powder loading used which is 67 vol. $\%$.

Table 1 summarizes the density and hardness value of each sample at different sintering temperatures. The highest relative density achieved was $93 \%$ and the hardness $540 \mathrm{Hv}$ at sintering temperature of $1350{ }^{\circ} \mathrm{C}$. The hardness result is higher than $\mathrm{CoCr}$ alloy produced by hot pressed done by Henriques et al. ${ }^{8)}$ which the highest hardness achieved was $492 \mathrm{Hv}$. While in this study, the sintering temperature of $1250{ }^{\circ} \mathrm{C}$ produced the lowest relative density of $76 \%$ and hardness of $200 \mathrm{Hv}$.

The effect of temperature on the sintering process can be observed clearly based on the morphology of the sintered surface as shown in Fig. 3. Low sintering temperature $\left(1250^{\circ} \mathrm{C}\right)$ resulted in low densification where the original shape of the particles were still can be seen clearly. Therefore, lower density was achieved. At

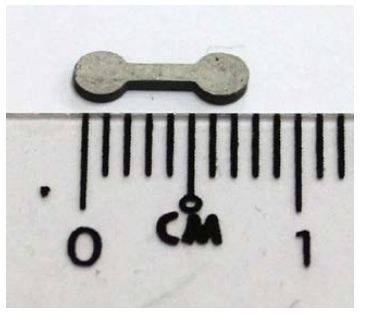

Fig. 2 Sintered part at $1350^{\circ} \mathrm{C}$.

Table 1 Shrinkage, relative density and hardness of sintered CoCrMo.

\begin{tabular}{cccc}
\hline $\begin{array}{c}\text { Sintering } \\
\text { Conditions }\end{array}$ & $\begin{array}{c}\text { Shrinkage } \\
(\%)\end{array}$ & $\begin{array}{c}\text { Relative density } \\
(\%)\end{array}$ & $\begin{array}{c}\text { Hardness } \\
(\mathrm{Hv})\end{array}$ \\
\hline $1350^{\circ} \mathrm{C}$ & 14 & 93 & $540 \pm 20$ \\
$1300^{\circ} \mathrm{C}$ & 13 & 87 & $400 \pm 25$ \\
$1250^{\circ} \mathrm{C}$ & 10 & 76 & $200 \pm 20$ \\
\hline
\end{tabular}

this point, the surface diffusion mechanism dominates the sintering process. These results are in good agreement with the results reported by Rodriguez et al. ${ }^{6}$ where low sintering temperature yielded poor density and tensile strength values in the powder compaction process of CoCrMo. When the temperature is increased to $1300^{\circ} \mathrm{C}$, necking between particles seemed to be grow and bonding between particles increased. At higher sintering temperature $1350{ }^{\circ} \mathrm{C}$, the powder metallurgical bonding occurs rapidly and become networked. Diffusion mechanisms become active during the heating process at high temperature and result in reduction of porosity. The energy supplied to the powder particles help powder to bond massively.

Fig. 4 shows the fracture surface of the specimen at sintering temperature of $1250^{\circ} \mathrm{C}$ and $1350{ }^{\circ} \mathrm{C}$. At low sintering temperature, high porosity leads to low strength specimen. At high sintering temperature, changes in structure and size reduction of porosity makes the bond formation between powders clearer. The strength increased with increasing in bonding formation between particles.

The mechanical properties of the sintered CoCrMo part are 

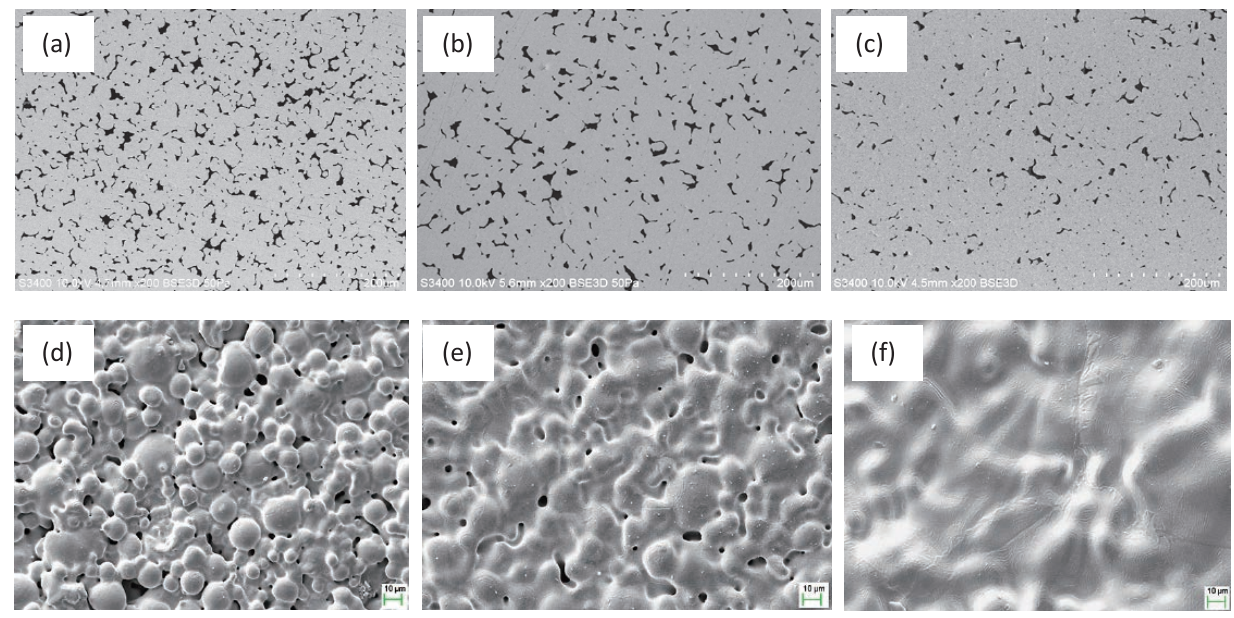

Fig. 3 Crossection and morphology of Sintered CoCrMo at (a) \& (d) $1250{ }^{\circ} \mathrm{C}$, (b) \& (e) $1250{ }^{\circ} \mathrm{C}$ and (c) \& (f) $1250{ }^{\circ} \mathrm{C}$.

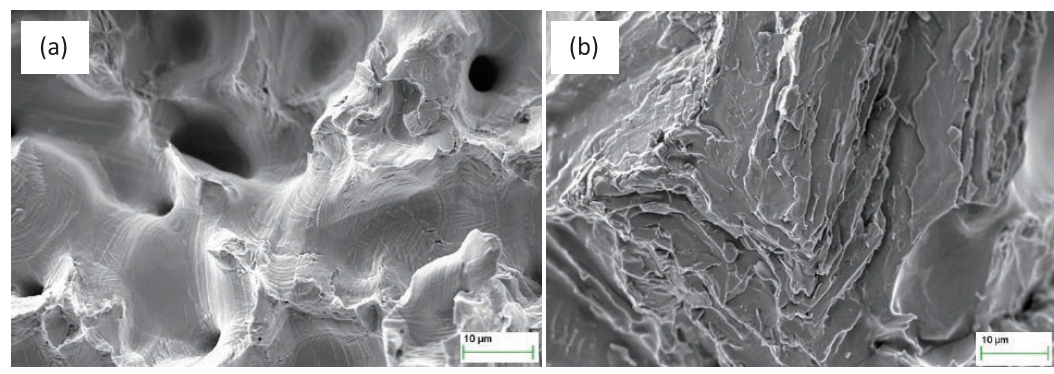

Fig. 4 Fracture surface of sintered $\mathrm{CoCrMo}$ at (a) $1250{ }^{\circ} \mathrm{C}$ and (b) $1350^{\circ} \mathrm{C}$.

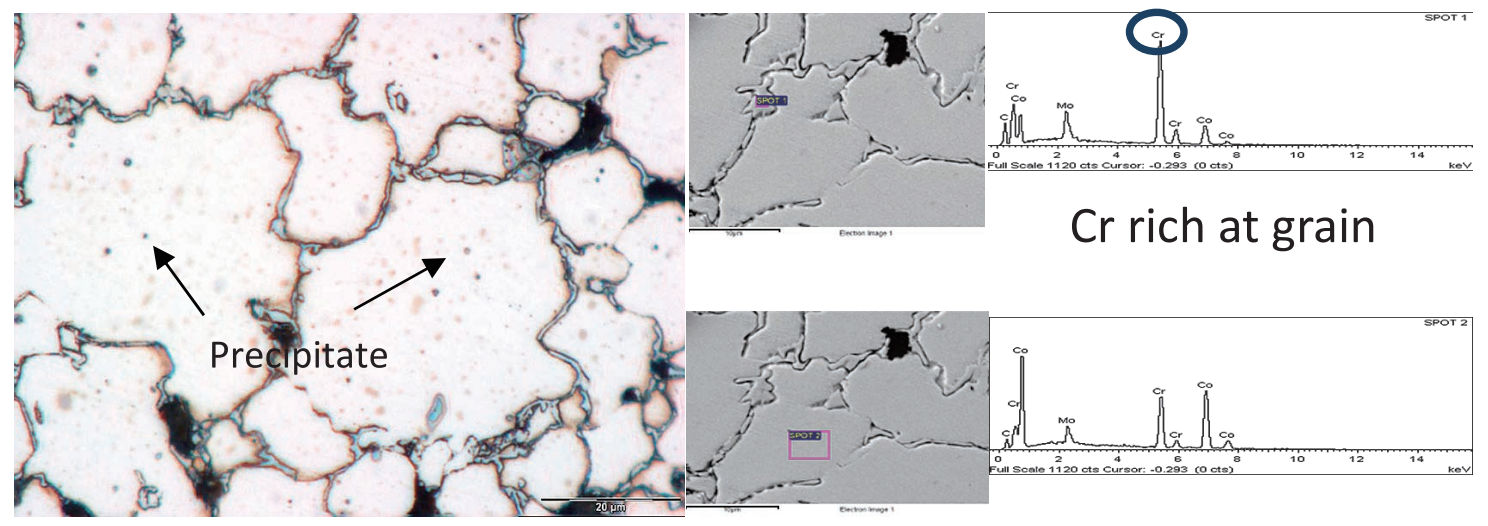

Fig. 5 Microstructure of Co30Cr6Mo.

summarized in Table 2. The highest tensile strength was achieved at sintering temperature of $1350{ }^{\circ} \mathrm{C}$ which meets ISO standard 5832-4. The increase in density and decrease in porosity affected the tensile strength of the sintered part. The ultimate strength increased as the density increased. From the mechanical properties of sintered CoCrMo part in Table 2, it can be concluded that at higher ultimate strength, the elongation tends to be lower. At low sintering temperature, the specimens are experienced to have low strength and fragile behavior. Few adjustment in the process sintering conditions need to be done in the future as only parts at sintering temperature $1350{ }^{\circ} \mathrm{C}$ meet the ISO 5832-4 standard.

The microstructure of sintered CoCrMo is shown in Fig. 5.
Table 2 Mechanical properties of sintered Co30Cr6Mo.

\begin{tabular}{cccc}
\hline Sintering Temperature & $\begin{array}{c}\text { Proof Strength } \\
(\mathrm{MPa})\end{array}$ & $\begin{array}{c}\text { Ultimate Strength } \\
(\mathrm{MPa})\end{array}$ & $\begin{array}{c}\text { Elogations } \\
(\%)\end{array}$ \\
\hline $\mathbf{1 3 5 0}{ }^{\circ} \mathbf{C}$ & $\mathbf{4 9 0}$ & $\mathbf{7 0 0} \pm \mathbf{2 0}$ & $\mathbf{1 0}$ \\
$1300^{\circ} \mathrm{C}$ & 400 & $650 \pm 20$ & 11 \\
$1250^{\circ} \mathrm{C}$ & 340 & $400 \pm 20$ & 13 \\
ISO $5832-4$ & 450 & 655 & $>8$ \\
Implant for surgery & & & \\
\hline
\end{tabular}

From SEM micrograph, grayish and blocky type precipitation exist along the grain boundary of the sintered parts which was the same as reported by Giacchi et. al $2011^{3)}$. From EDAX analysis, the Cr- 
rich carbides exist at the grain boundary. The carbon content after sintering process was $0.05 \mathrm{wt} \%$. This is may be due to excess of carbon after debinding process. However, based on ASTM F2924 for Ti6AL4V the carbon content should not exceed $0.1 \mathrm{wt} \%$.

\section{Summary}

Sintering temperature has significant effect on the density, hardness and strengths of sintered CoCrMo. Higher densification part was produced at higher sintering temperature conducted at $1350{ }^{\circ} \mathrm{C}$ compared with $1300{ }^{\circ} \mathrm{C}$ and $1250{ }^{\circ} \mathrm{C}$. The highest relative density was achieved at $93 \%$ of the theoretical value. While the highest ultimate strength and hardness was $700 \mathrm{MPa}$ and $540 \mathrm{Hv}$, respectively. Sintered CoCrMo at $1350{ }^{\circ} \mathrm{C}$ can meet the ISO 5832-4 standard.

\section{References}

1) D. Williams: "Tribo-corrosion properties of cobalt-based medical implant alloys in simulated biological environments", Wear, 263 (2007) 1105-1111.

2) W. C. Rodriguez, L. R. Broilo, L. Schaeffer, G. Knornschild, F. R. M Espinoza: "Powder metallurgical processing of $\mathrm{Co}-$ $28 \% \mathrm{Cr}-6 \%$ Mo for dental implants: Physical, mechanical and electrochemical properties”, Powder Technology, 206 (2011) 233-238.
3) J. V. Giacchi, C. N. Morando, O. Fornaro, H. A. Palacio: "Microstructural Characterization of as-cast biocompatible Co-Cr-Mo", Materials Characterization, 62 (2011) 53-61.

4) M. H. I. Ibrahim, N. Muhamad, A. B. Sulong: "Rheological investigation of water atomised stainless steel powder for micro metal injection molding”, Int. J. Mech, Mater. Eng., 4 (2009) 1-8.

5) M. Podrez-Radziszewska, K. Haimann, W. Dudziński, M. Morawska-Sołtysik: "Characteristic of intermetallic phases in cast dental CoCrMo alloy", Archives of Foundry Engineering., 10 (3) (2010) 51-56.

6) K. P. Gupta: "The Co-Cr-Mo (Cobalt-Chromium-Molybdenum) System", Journal of Phase Equilibiria and Diffusion, 26 (1) (2005) 87-92.

7) R. M. German: Sintering Theory and Practice, John Wiley \& Sons, Inc. (1996) 534.

8) B. Henriques, A. Bagheri, M. Gasik, J. C. M. Souza, O. Carvalho, F. S. Silva, R. M. Nascimento: "Mechanical properties of hot pressed CoCrMo alloy compacts for biomedical applications", Materials \& Design, 83 (2015) 829-834. 